\title{
A Preliminary Study on the Measurement of Sediment Concentration in Hill-Slope Runoff with an Electrolyte Tracer
}

\author{
Xiaonan Shi ${ }^{*}$ and Fan Zhang \\ Key Laboratory of Tibetan Environment Changes and Land Surface Processes, Institute of Tibetan Plateau Research, \\ Chinese Academy of Sciences, Beijing, China
}

Received 9 September 2011, accepted 23 May 2012

\begin{abstract}
Sediment concentration in hill-slope runoff is an important index for soil erosion. Developing a reliable and portable measuring system of sediment concentration is a core issue for soil and water conservation study, especially for the Tibetan Plateau under unfavorable climate and terrain conditions for field investigation. Challenges include uneven distribution of sediment across a runoff section as well as difficulty in detecting a wide range of particle sizes. An electrolyte tracer, with the advantage of uniform distribution and its widely used electric-conductivity sensor, can avoid the problems of direct measurement of sediment. A new measurement method of sediment concentration in runoff with an electrolyte tracer is proposed based on a premise that sediment concentration is closely correlated with hydrodynamic dispersion coefficient of solute in runoff. In this study, an experiment system of hill-slope runoff with an electrolyte tracer and sediments is first designed. Second, two model parameters in the advective-dispersive equation of solute transport, flow velocity and diffusion coefficient, are inversely estimated by calibrating the observed concentrations of an electrolyte tracer. And third, the relationship between sediment concentrations and hydrodynamic dispersion coefficients are defined through specified regression. As a result, a measurement system of sediment concentration in hill-slope runoff with an electrolyte tracer is primarily established by integrating the relationship of variables, experiment system, and model theory.
\end{abstract}

Key words: Sediment concentration, Hill-slope runoff, Measurement method, Electrolyte tracer, Hydrodynamic dispersion coefficient Citation: Shi, X. and F. Zhang, 2012: A preliminary study on the measurement of sediment concentration in hill-slope runoff with an electrolyte tracer. Terr. Atmos. Ocean. Sci., 23, 597-604, doi: 10.3319/TAO.2012.05.23.01(WMH)

\section{INTRODUCTION}

Sediment concentration is an important index with respect to the mechanics of erosion, environmental impact monitoring, and reservoir capacity safety. Investigations by the Remote Sensing Center in the Ministry of Water Resources of China, indicated that the total acreage affected by soil erosion was $3670000 \mathrm{~km}^{2}, 38.2 \%$ of the total area of the nation (Jiang 1997) and of which $1790000 \mathrm{~km}^{2}$ had been under influence of moderate to severe soil and water losses (Li et al. 2005). In the Tibet Autonomous Region of China, the area of soil erosion reached to $1034200 \mathrm{~km}^{2}$ that nearly account to $85 \%$ of its total land area (Zhang et al. 2003). Under the conditions of fragile surface ecology, abrupt terrain, together with enhanced human activity, the issues of soil

\footnotetext{
* Corresponding author

E-mail: shixiaonan@itpcas.ac.cn
}

degradation and river sand deposition aroused by soil erosion have received much attention. As reported by Wen et al. (2002), sediment yield and sediment content in Yalungtsangpo posed increasing tendencies in current decades. The Lhasa river, a main Branch to the Yalungtsangpo, contributes $180 \times 10^{4} \mathrm{t}$ sediments in 1990 s which increased $87.9 \%$ compared with $95.8 \times 10^{4} \mathrm{t}$ in the $1960 \mathrm{~s}$. Model simulation has proved to be an effective prediction tool for soil and water protection management. Accurate measures of sediment concentration in rivers and canals are necessary to develop reliable models for soil erosion.

There are many methods used to measure sediment concentration. Due to different principles, the applicability and precision of each type of method is different. They can be classified as direct and indirect methods (see Table 1). The direct methods, including a traditional oven-dry and pycnometer method are still widely used for measuring 
Table 1. Commonly-used measurement methods for sediment concentrations.

\begin{tabular}{|c|c|c|c|}
\hline Types & Methods & Limitations & References \\
\hline \multirow{2}{*}{ Direct method } & Oven-dry & \multirow{2}{*}{ Labor and time consuming } & \multirow{2}{*}{ Abrahams et al. 1993; Zobisch et al. 1996} \\
\hline & Pycnometer & & \\
\hline \multirow{5}{*}{ Indirect method } & Capacitance-based & $\begin{array}{l}\text { Sensitive to temperature and } \\
\text { salinity content }\end{array}$ & Li et al. 2005; Schlaberg et al. 2006 \\
\hline & Acoustics & $\begin{array}{l}\text { Disturb water flow state; } \\
\text { limited scale }\end{array}$ & $\begin{array}{l}\text { Hay and Sheng 1992; Thorne et al. 1993; } \\
\text { Huang et al. 1995; Thorne and Hanes } 2002\end{array}$ \\
\hline & Optics & $\begin{array}{l}\text { Sensitive to sizes, shapes and } \\
\text { distribution of sediments }\end{array}$ & $\begin{array}{l}\text { Vos et al. 2000; Campbell et al. 2005; } \\
\text { Orwin and Smart } 2005\end{array}$ \\
\hline & Laser & \multirow{2}{*}{$\begin{array}{l}\text { Expensive, in large size, } \\
\text { harmful radiation }\end{array}$} & \multirow{2}{*}{ Lei et al. 2002} \\
\hline & $\gamma$-ray & & \\
\hline
\end{tabular}

suspended sediment concentration in runoff but are time and labor intensive (Abrahams et al. 1993; Zöbisch et al. 1996). Indirect methods use instruments based on principles of capacitance, acoustics, optics, laser, $\gamma$-Ray, and so on. The capacitance-based method is quite sensitive to temperature and salinity content in flow water ( $\mathrm{Li}$ et al. 2005; Schlaberg et al. 2006). The acoustic method disturbs the state of water flow and hence changes hydrodynamic properties of the flow. The influence is magnified as sediment concentrations raises (Hay and Sheng 1992; Thorne et al. 1993; Huang et al. 1995; Thorne and Hanes 2002). Optical devices emit light and then measure the total reflected light, which is proportional to sediment concentration. They need calibration under practical conditions such as overlapping shade, non-uniform distribution of concentration, and sizes and shapes of particles (Vos et al. 2000; Campbell et al. 2005; Orwin and Smart 2005). Laser- and $\gamma$-ray-based devices, with high-resolution temporal and spatial coherence, are able to efficiently reduce noises and disturbances from outside (Lei et al. 2002); however, these devices are usually very expensive and large. In addition, the threat from radiation also limits their application (Bale and Morris 1987). To summarize, there are still no satisfactory methods for practical measurement of sediment concentrations in hill-slope runoff necessitating an accurate and reliable measurement of sediment concentration (Ouilon et al. 1997; Kao et al. 2005).

During soil erosion processes on a hill slope, suspended sediment in flow will change bulk density and velocity of flow water in a positive correlation with sediment concentration in flow water. Both bulk density and flow velocity are crucial variables directly affecting solute transport which is reflected by the parameter of hydrodynamic dispersion coefficient in convection-diffusion equation governing solute transport. In previous studies, it has been reported that the mechanical dispersion coefficient of solute is a function of flow velocity and suspended sediment concentration (Bresler 1973; van Genuchten et al. 1980, 1989). Therefore, there must be some relationship between hydrodynamic dispersion coefficients and suspended sediment concentrations. As is well-known, the hydrodynamic dispersion coefficient, as a parameter in convection-diffusion equation, can be calculated inversely by modelling the transport of an electrolyte tracer (Shi et al. 2012). If the relationship between hydrodynamic dispersion coefficients and sediment concentrations of water flow can be revealed, the sediment concentration can be determined.

In our study, a new method is proposed to measure suspended sediment concentration in hill-slope runoff with an electrolyte tracer. An experiment with regard to hill-slope runoff using an electrolyte tracer and sediments is first conducted to register the electrolyte transport by electricconductivity sensors. The mathematical model of the advective-dispersion equation is then employed to simulate the observed electrolyte concentration in water flow with different sediment concentrations and thus inversely calculate flow velocities and hydrodynamic dispersion coefficients of solute. Finally, through an analysis of the relationship between hydrodynamic dispersion coefficients and sediment concentration, a method of sediment concentration measurement with an electrolyte tracer can be defined. The newly-proposed method can avoid the problems caused by irregular sizes and shapes of particles or non-uniform distribution of concentration which are common issues.

\section{THEORETICAL BACKGROUND}

Electrolyte in water flow is transported under influences of both convection and dispersion. When rainfall and infiltration can be ignored, the convection and dispersion processes of electrolyte in a steady state water flow are given as:

$\frac{\partial C}{\partial t}+u \frac{\partial C}{\partial x}=\frac{\partial}{\partial x}\left(D_{H} \frac{\partial C}{\partial x}\right)$ 
where $\mathrm{C}\left(\mathrm{kg} \mathrm{m}^{-3}\right)$ is the electrolyte concentration, which is a function of distance along slope $x(\mathrm{~m})$ and time $t(\mathrm{~s})$, and proportional to the electrical conductivity of the solution; $u$ $\left(\mathrm{m} \mathrm{s}^{-1}\right)$ is the flow velocity; and $D_{H}\left(\mathrm{~m}^{2} \mathrm{~s}^{-1}\right)$ is the hydrodynamic dispersion coefficient.

The upper boundary condition is given as a pulse function, that is:

$C(x, t) / C_{0}=\delta\left(t=t_{0}\right), \quad x=0$

where $\delta(t)$ is the pulse function from the upstream injector with normalized concentration $C_{0}$. The normalized concentration is calculated as:

$C_{0}=\int_{0}^{\infty} C(x, t) d \tau$

The lower boundary condition is given as:

$C(x, t)=0, \quad x=\infty$

The initial condition is set to be zero along the whole slope:

$C(x, t)=0, \quad t=0$

With Laplace's transformation, the analytical solution of Eqs. (1) - (5) was obtained as the following:

$C(x, t) / C_{0}=\frac{x}{2 t \sqrt{\pi D_{H} t}} \exp \left[-\frac{(x-u t)^{2}}{4 D_{H} t}\right]$

There are two important parameters, i.e., $u$, and $D_{H}$, to be determined to specify the functional distribution of the transient transport process. The parameters can be calculated by a fitting model solution, Eq. (6), with the experimentally obtained data sets using the least squares method (LSM). The experimentally obtained solute transport processes, at a given location are recorded in the form of $\hat{C}\left(X, t_{i}\right), i=1,2$, $\ldots, N$, where, $X$ is the distance to the first sensor that is used to monitor the upper boundary condition. $N$ is the number of measurement time points.

The calculated solutions $C\left(X, t_{i}\right)$ using Eq. (6) with $x$ $=X$, are fitted to the measurement $\hat{C}\left(X, t_{i}\right)$. The sum of the squared errors is given as:

$$
\Delta=\sum_{i=1}^{N}\left[C\left(X, t_{i}\right)-\hat{C}_{i}\left(X, t_{i}\right)\right]^{2}
$$

The next step of the least squares method is to inversely determine the best fit parameters, $u$ and $D_{H}$ in Eq. (5) so as to minimize the $\Delta$ function, given in Eq. (7). That requires:

$\frac{\partial \Delta}{\partial u}=0$

$\frac{\partial \Delta}{\partial D_{H}}=0$

or

$\Sigma\left[C\left(X, t_{i}\right)-\hat{C}_{i}\left(X, t_{i}\right)\right] \frac{\partial C}{\partial u}=0$

$\sum\left[C\left(x, t_{i}\right)-\hat{C}_{i}\left(X, t_{i}\right)\right] \frac{\partial C}{\partial D_{H}}=0$

In which,

$$
\begin{aligned}
& \frac{\partial C}{\partial u}=C_{0} \frac{X}{2 t_{i} \sqrt{\pi D_{H} t_{i}}} \frac{\left(X-u t_{i}\right)}{2 D_{H}} \exp \left[-\frac{\left(X-u t_{i}\right)^{2}}{4 D_{H} t_{i}}\right] \\
& \frac{\partial C}{\partial D_{H}}=C_{0} \frac{X}{2 t_{i} \sqrt{\pi D_{H}^{3} t_{i}}}\left[\frac{\left(X-u t_{i}\right)^{2}}{4 D_{H} t_{i}}-\frac{1}{2}\right] \exp \left[-\frac{\left(X-u t_{i}\right)^{2}}{4 D_{H} t_{i}}\right]
\end{aligned}
$$

Eqs. (9), (10) are used to estimate the flow velocity, $u$, and the hydrodynamic dispersion coefficient, $D_{H}$ by fitting the solution to the experimentally obtained data.

\section{EXPERIMENTAL METHOD}

The experimental data of solute transport in shallow water with a sediment concentration was collected to estimate the velocity of water flow and hydrodynamic dispersion coefficient with model simulation. The experimental system includes a computer installed with specially designed software for control of electrolyte injection, sensed data logging and data analysis, interface unit, electric conductivity sensors, salt solute injector, and flume and watersupply tank (see Fig. 1). The experiment flume is $4 \mathrm{~m}$ long by $15 \mathrm{~cm}$ wide by $50 \mathrm{~cm}$ high. The bottom of the flume was paved with sand paper to imitate the roughness of soil surface. The slope of the flume was set at 4 degrees and the discharge of water flow is $24 \mathrm{~L} \mathrm{~min}^{-1}$. The water flow with a certain sediment concentration is supplied using a tank with $5 \mathrm{~m}$ water head. In the tank a mixer is used to keep mixing the soil with water. The texture of the soil used in the experiments is listed in Table 2. Eight treatments with different sediment concentration $(\mathrm{S})$ in water flow were set in our study, i.e., 0 (clear water), 45, 120, 240, 380, 500, 630, 750 $\mathrm{kg} \mathrm{m}^{-3}$, respectively. 


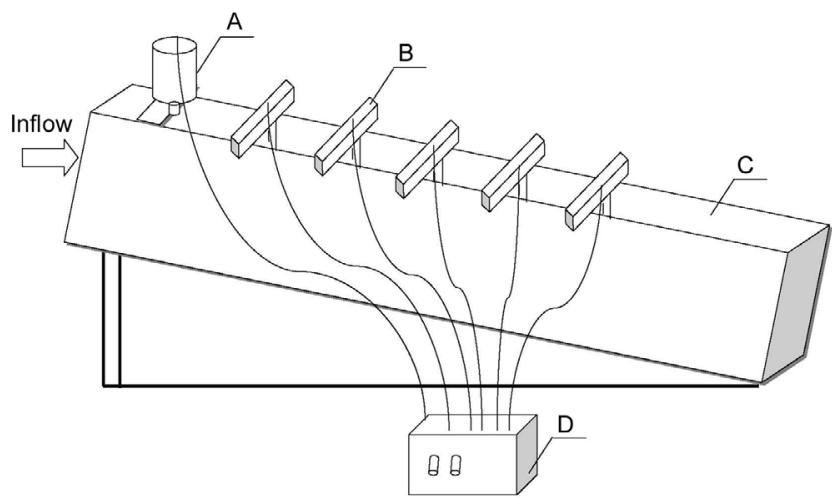

Fig. 1. A sketch map of experimental apparatus. A is the electrolyte injector; B is electric conductivity sensor; C is water flume; D is data logger and auto-controller of electrolyte injection which is connected to a computer installed with a specially designed software; and a water-supply tank in $1 \mathrm{~m}^{3}$ volume is not included in the figure.

Table 2. Texture of the soil used in experiments.

\begin{tabular}{l|ccccc}
\hline Diameter (mm) & $\leq 0.001$ & $\leq 0.005$ & $\leq 0.01$ & $\leq 0.05$ & $\leq 1$ \\
\hline Proportion (\%) & $9.40 \%$ & $12.5 \%$ & $16.7 \%$ & $77.3 \%$ & $100 \%$ \\
\hline
\end{tabular}

After the water flow reached a steady state when the output discharge is independent on time, nearly saturated salts, such as $\mathrm{KCl}, \mathrm{NaCl}, \mathrm{KBr}, \mathrm{NaBr}$, etc. with concentrations high enough for $\mathrm{EC}$ (electric conductivity) sensor detection serve as $\mathrm{EC}$ tracers. In this study, $\mathrm{KCl}$ solution was injected into the water flow at the upper end of the flume. The period of a solution injection managed by a computercontrolled electrical valve, lasted about $0.6 \mathrm{~s}$. The sensors for EC measurements were set up downstream at $0.5,1.0$, $1.5,2.0$, and $2.5 \mathrm{~m}$ from the solution injection point. The EC values were logged into a computer at 100 data points per second. The sensed data were used to fit the model solution, as described above to determine the required parameters, namely the flow velocity $u$ and the hydrodynamic dispersion coefficient $D_{H}$.

\section{RESULTS AND DISCUSSION}

Figure 2 shows the solute transport processes as described by the experimental data (symbols) and the fitted data with model simulation (smooth curves) under the different conditions of sediment concentrations. The flow velocity $u$ and the hydrodynamic coefficient $D_{H}$ were determined for different treatments through the model calibration. The fitted coefficients, the coefficient of determination $\left(R^{2}\right)$ and the mean squared error (MSE) were also calculated and are listed in Table 3.

As shown in Fig. 2, the five peaks in each plot are reg- istered by five sensors located downstream at $0.5,1.0,1.5$, 2.0 , and $2.5 \mathrm{~m}$ away from electrolyte injector. The model captured the solute transport processes as measured at five positions as well. The model simulation closely followed the peak position and the rising and falling limbs of the experiment data. As given by the measured and modeled data sets, under the same experimental conditions the peaks of the curves decreased with distance from the source point due to dispersion. As the sediment concentration increased, the breakthrough time of the concentration curve increased and the concentration distribution became more dispersive. The model simulation seemed to hardly fit the faster rising and slower falling trends of the concentration curves for the treatments with higher sediment concentrations, such as the treatments of $S=500,630,750 \mathrm{~kg} \mathrm{~m}^{-3}$. Dispersion states of electrolyte in water flow depend on both sediment concentration and flow velocity. Under our studied conditions with discharge of $24 \mathrm{~L} \mathrm{~min}^{-1}$ and slope gradient of 4 degree, simulation accuracy of the method significantly decreased as the sediment concentration became larger than $500 \mathrm{~kg} \mathrm{~m}^{-3}$, possibly because that the complex effects of quicker mixing and deposition of sediments with higher concentration were not simulated; however, an instructional sediment concentration range for this operation under various conditions may not be conclusively defined based on current results.

The coefficients of determination calculated for all the experimental treatments are mostly greater than 0.9 . The values of MSEs are all very small and showed a consistency with the change of $R^{2}$. As the sediment concentration in a water flow increased, the $R^{2}$ showed decreasing tendencies and the MSEs showed increasing trends (see Fig. 3). The results indicated the model simulations for higher sediment concentrations are not as good as those for lower sediment concentrations. It is probably because that sediment accelerates mixing and dispersion of electrolytes which will cause a mass loss in the electrolyte(s) registered by EC sensors.

The estimated velocities of shallow water flow for different sediment concentrations are plotted in Fig. 4. The velocity values showed a decreasing tendency with sediment concentration and gradually approached steady as sediment concentration increases. The velocities are assumed to be the same among the series of experiments due to the same discharge and slope setting. However, the differences of calculated velocities may be attributed to the existence of sediment in water flow which may increase the bulk density and viscosity of water. More theoretical and experimental studies for further explanation are needed in the future.

The hydrodynamic dispersion coefficient reflects the influences of flow velocity and media property. The values of the hydrodynamic dispersion coefficient increased with sediment concentration (Fig. 5). A formula to calculate sediment concentration with hydrodynamic dispersion coefficient is built by employing linear regression, presented in Eq. (11). 

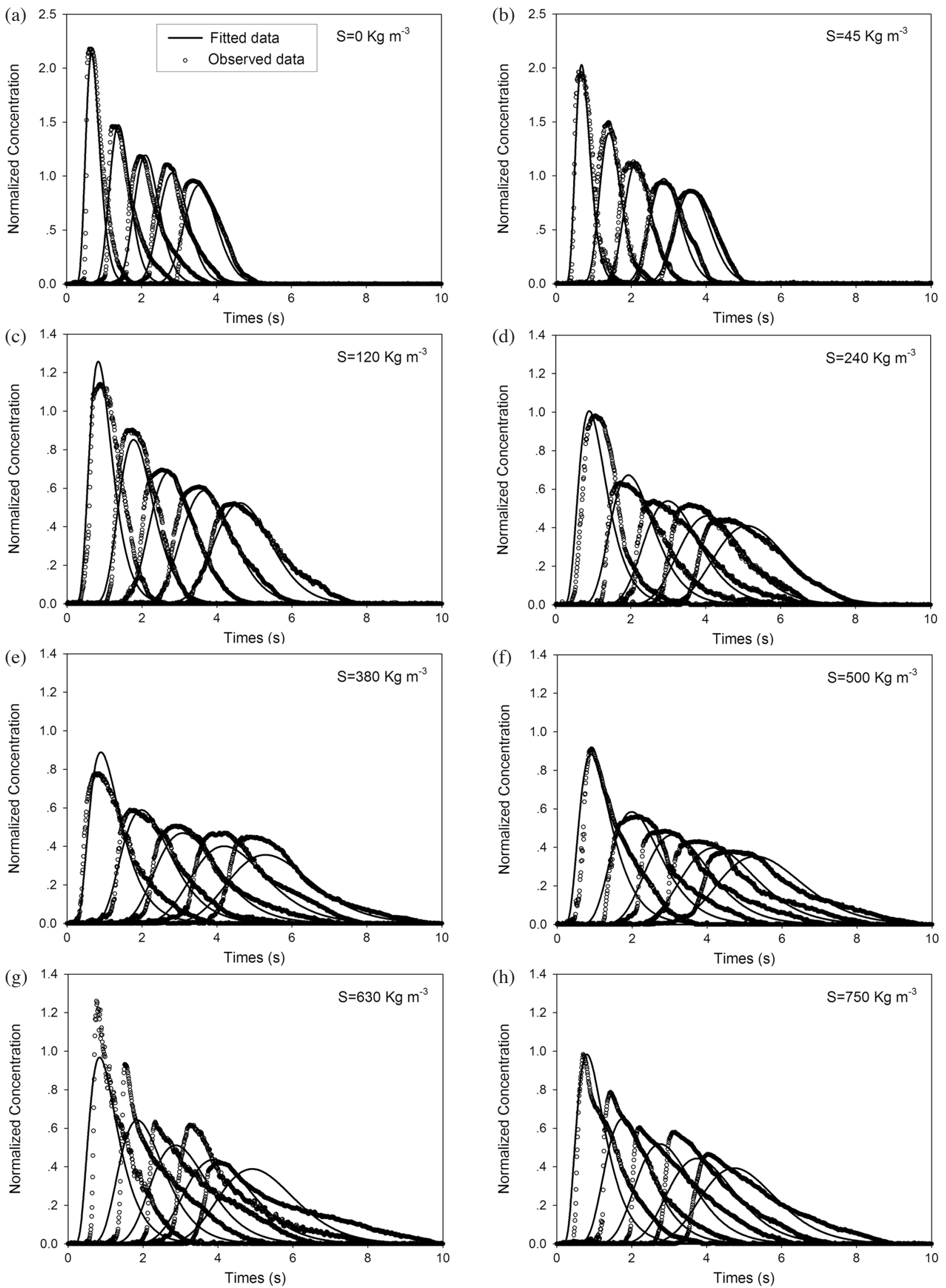

Fig. 2. Solute transport processes: measured data (symbols) and fitted data (lines) for 0, 45, 120, 240, 380, 500, 630, 750 kg m-1 sediment concentrations in water flow. $S$ is sediment concentration in flow water. 
Table 3. Estimated parameters and determination coefficients obtained through model calibration.

\begin{tabular}{ccccc}
\hline $\begin{array}{c}\text { Sediment concentration } \\
\left(\mathbf{k g ~ m}^{-3}\right)\end{array}$ & $\boldsymbol{u}\left(\mathbf{m ~ s}^{-1}\right)$ & $\boldsymbol{D}_{H}\left(\times \mathbf{1 0}^{-2} \mathbf{~ m}^{2} \mathbf{~ s}^{-1}\right)$ & $\mathbf{R}^{2}$ & MSE $\left(\times \mathbf{1 0}^{-3}\right)$ \\
\hline 0 & 0.695 & 1.301 & 0.941 & 5.521 \\
45 & 0.683 & 1.379 & 0.975 & 2.322 \\
120 & 0.527 & 1.771 & 0.956 & 2.247 \\
240 & 0.473 & 2.105 & 0.917 & 3.071 \\
380 & 0.453 & 2.476 & 0.954 & 1.386 \\
500 & 0.452 & 2.511 & 0.913 & 2.546 \\
630 & 0.488 & 2.602 & 0.833 & 5.936 \\
750 & 0.505 & 2.835 & 0.905 & 3.348 \\
\hline
\end{tabular}

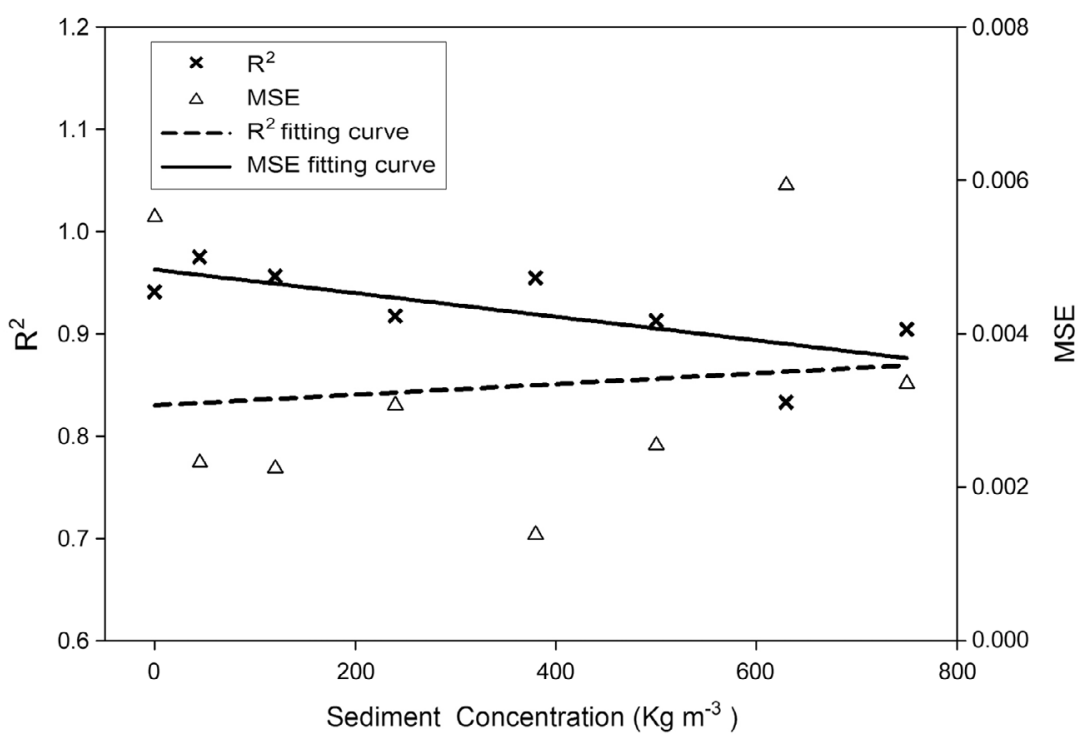

Fig. 3. Changes of simulated coefficients with sediment concentrations.

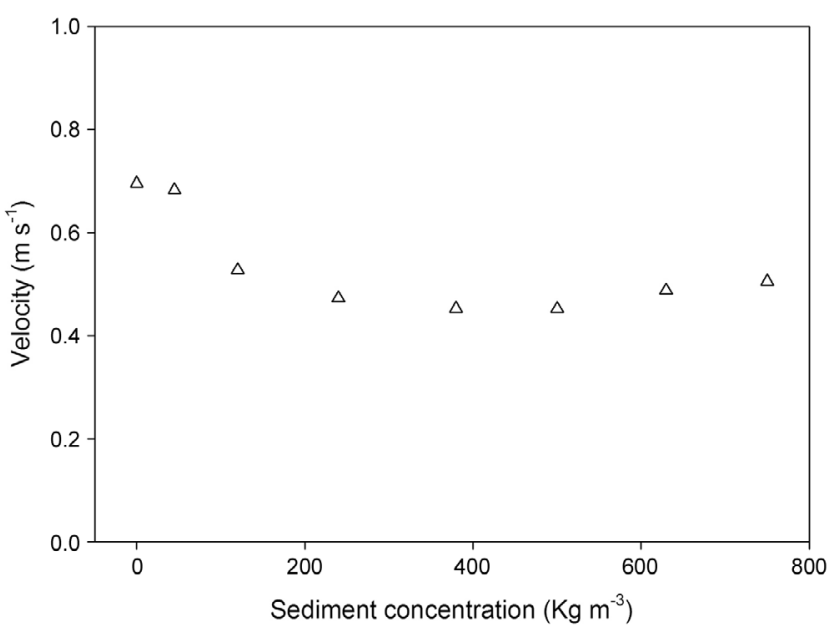

Fig. 4. Changes in velocities of water flow with sediment concentrations.

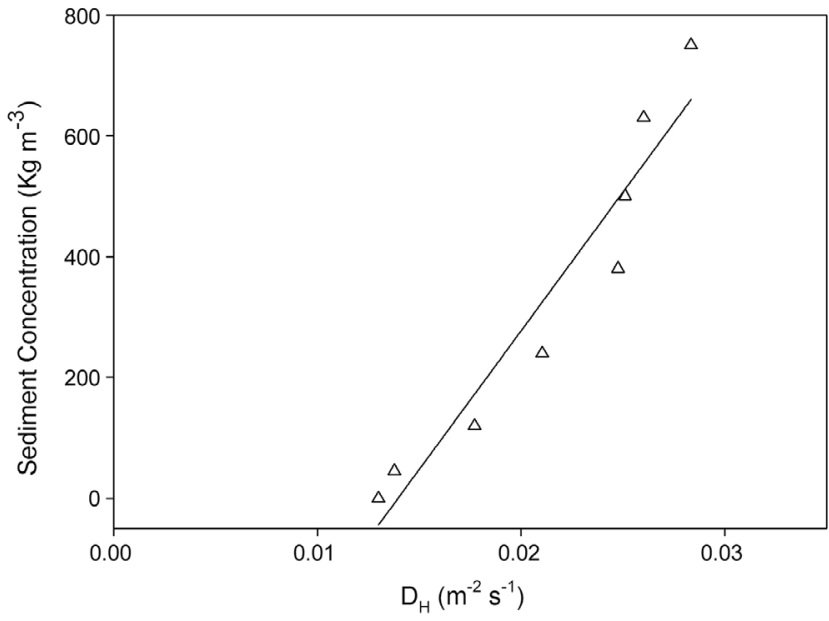

Fig. 5. Changes in hydrodynamic dispersion coefficients with regard to sediment concentrations. 
$S=4.5886 \times 10^{4} \times D_{H}-6.4081 \times 10^{2}$ with $R^{2}=0.9602$

in which, $S\left(\mathrm{~kg} \mathrm{~m}^{-3}\right)$ is sediment concentration in water flow.

If the variability of flow velocity among treatments is neglected, the changing tendency of hydrodynamic dispersion coefficient reflects the effect of sediment concentration. The relationship between hydrodynamic dispersion coefficient and sediment concentration does not follow a strict linear correlation.

We also attempted to employ quadratic polynomial to fit the data and derived another formula to calculate sediment concentration as Eq. (12).

$$
\begin{aligned}
S= & 2.8767 \times 10^{6} \times D_{H}^{2}-7.0951 \times 10^{4} \times D_{H}+4.5805 \times 10^{2} \\
& \text { with } R^{2}=0.9875
\end{aligned}
$$

The determination of coefficients for both regressions is high. However, the empirical formulas lack support of physically-based evidence. A conclusive relationship seems to be hardly defined based on current eight experimental data sets. In addition, we still have limited knowledge about the physical process or interaction of sediment concentration with hydrodynamic dispersion coefficient.

\section{CONCLUSIONS}

Sediment concentration in hill-slope runoff is an important index for soil conversation and hydraulic engineering safety. A new measurement method of sediment concentration in runoff with an electrolyte tracer is proposed. First, experiments of hill-slope runoff with an electrolyte tracer and various sediments concentration were performed. The electrolyte concentrations were temporally registered by EC sensors located at various measurement positions. Two model parameters, a flow velocity and hydrodynamic dispersion coefficient, were inversely estimated by fitting model calculations to the observed concentration data. The relationship between hydrodynamic dispersion coefficient and sediment concentration was analyzed. Two formats of formulas were built for sediment concentration measurement from a preliminary experiment analysis. Although determination coefficients for both regression formulas are high, the empirical formulas lack support of physically-based evidence. The effect of flow velocity on measured sediment concentration is not considered in this study which may play a role to measured sediment concentration and demand further investigation. Moreover, simulations for higher sediment concentrations are not as good as those for lower sediment concentrations. Determination of measurement ranges under various conditions relies on further studies.

Acknowledgements This work was supported by the Ministry of Science and Technology of the People's Republic of
China, Global Change Research Program (2010CB951702), the Chinese Academy of Sciences (CAS) Knowledge Innovation Program (KZCX2-EW-112), the National Natural Science Foundation of China (41101252, 41190082, 41001034), the Chinese Academy of Sciences (CAS) "Hundred Talent" Program, and China Post doctoral Science Foundation (20110490638).

\section{REFERENCES}

Abrahams, A. D. and J. F. Atkinson, 1993: Relation between grain velocity and sediment concentration in overland flow. Water Resour. Res., 29, 3021-3028, doi: 10.10 29/93WR00771. [Link]

Bale, A. J. and A. W. Morris, 1987: In situ measurement of particle size in estuarine waters. Estuar. Coast. Shelf Sci., 24, 253-263. doi: 10.1016/0272-7714(87)900680 . [Link]

Bresler, E., 1973: Simultaneous transport of solutes and water under transient unsaturated flow conditions. Water Resour. Res., 9, 975-986, doi: 10.1029/WR009 i004p00975. [Link]

Campbell, C. G., D. T. Laycak, W. Hoppes, N. T. Tran, and F. G. Shi, 2005: High concentration suspended sediment measurements using a continuous fiber optic instream transmissometer. J. Hydrol., 311, 244-253, doi: 10.1016/j.jhydrol.2005.01.026. [Link]

Hay, A. E. and J. Sheng, 1992: Vertical profiles of suspended sand concentration and size from multifrequency acoustic backscatter. J. Geophys. Res., 97, 1566115677, doi: 10.1029/92JC01240. [Link]

Huang, B. S., T. L. Teng, and Y. T. Yeh, 1995: Numerical modeling for acoustic scattering of 3-D spherical wavefronts: Implications on near source basin amplification. Terr. Atmos. Ocean. Sci., 6, 251-270.

Jiang, N. S., 1997: Soil loss and its prevention in China. Sediment Res., 2, 83-86.

Kao, S. J., T. Y. Lee, and J. D. Milliman, 2005: Calculating highly fluctuated suspended sediment fluxes from mountainous rivers in Taiwan. Terr. Atmos. Ocean. Sci., 16, 653-675.

Lei, T., H. Wang, J. Zhao, Q. Liu, and W. Xia, 2002: Automatic system for dynamical determination of sediment concentration and flow rate in runoff. Trans. CSAE, 18, 48-51.

Li, X., T. Lei, W. Wang, Q. Xu, and J. Zhao, 2005: Capacitance sensors for measuring suspended sediment concentration. Catena, 60, 227-237, doi: 10.1016/j. catena.2005.01.001. [Link]

Orwin, J. F. and C. C. Smart, 2005: An inexpensive turbidimeter for monitoring suspended sediment. Geomorphology, 68, 3-15, doi: 10.1016/j.geomorph.2004.04. 007. [Link] 
Ouilon, S., P. Forget, J. M. Froidefond, and J. J. Naudin, 1997: Estimating suspended matter concentrations from SPOT data and from field measurements in the Rhone River plume. Mar. Technol. Soc. J., 31, 15-20.

Schlaberg, H. I., J. H. Baas, M. Wang, J. L. Best, R. A. Williams, and J. Peakall, 2006: Electrical resistance tomography for suspended sediment measurements in open channel flows using a novel sensor design. Part. Part. Syst. Charact., 23, 313-320, doi: 10.1002/ppsc. 200601062. [Link]

Shi, X., F. Zhang, T. Lei, R. Chuo, S. Zhou, and Y. Yan, 2012: Measuring shallow water flow velocity with virtual boundary condition signal in the electrolyte tracer method. J. Hydrol., 452-453, 172-179, doi: 10.1016/ j.jhydrol.2012.05.046. [Link]

Thorne, P. D. and D. M. Hanes, 2002: A review of acoustic measurement of small-scale sediment processes. Cont. Shelf Res., 22, 603-632, doi: 10.1016/S0278-4343(01) 00101-7. [Link]

Thorne, P. D., P. J. Hardcastle, and R. L. Soulsby, 1993: Analysis of acoustic measurements of suspended sediments. J. Geophys. Res., 98, 899-910, doi: 10.1029/
92JC01855. [Link]

van Genuchten, M. T., 1980: A closed form equation for predicting the hydraulic conductivity of unsaturated soils. Soil Sci. Soc. Am. J., 44, 892-898.

van Genuchten, M. T. and R. J. Wagenet, 1989: Two-site/ two-region models for pesticide transport and degradation: Theoretical development and analytical solutions. Soil Sci. Soc. Am. J., 53, 1303-1310.

Vos, R. J., P. G. J. ten Brummelhuis, and H. Gerritsen, 2000: Integrated data-modeling approach for suspended sediment transport on a regional scale. Coast. Eng., 41, 177-200, doi: 10.1016/S0378-3839(00)00032-6. [Link]

Wen, A., S. Liu, J. Fan, and P. Zhu, 2002: Current change on sedimentation and control its method in middle Yalungtsangpo River. J. Soil Water Conserv., 16, 148-150.

Zhang, J., A. Wen, Z. Chai, S. Liu, and H. Li, 2003: Characteristics and status of the soil erosion in Tibet. J. Mt. Sci., 21, 148-252.

Zöbisch, M. A., P. Klingspor, and A. R. Oduor, 1996: The accuracy of manual runoff and sediment sampling from erosion plots. J. Soil Water Conserv., 51, 231-233. 